\title{
Stopped-Flow Spectrophotometric Assay of Glycerol Permeation in Escherichia coli: Applicability and Limitations
}

\author{
By MICHAEL O. EZE AND RONALD N. MCELHANEY \\ Department of Biochemistry, University of Alberta, \\ Edmonton, Alberta, Canada T6G $2 H 7$
}

(Received 20 September 1977)

\begin{abstract}
The passive permeation and facilitated diffusion of glycerol in various strains of Escherichia coli have been studied by stopped-flow spectrophotometry. Contrary to the prediction for glycerol entry by simple diffusion, the reciprocal relaxation time $\left(1 / \tau, \mathrm{s}^{-1}\right)$ for the passive permeation of glycerol in cells grown in the presence of glucose was not constant but decreased as the glycerol concentration increased above $100 \mathrm{~mm}$. This anomaly was not due to refractive index differences or to the presence of residual levels of the glycerol facilitator protein in non-induced cells. Although reciprocal relaxation times for glycerolinduced $E$. coli exhibited the expected elevation relative to non-induced cells, a similar anomalous decrease of $1 / \tau\left(\mathrm{s}^{-1}\right)$ with increasing glycerol concentration was observed. In addition, at early times after suspension in dilute buffer, the $1 / \tau\left(\mathrm{s}^{-1}\right)$ values obtained for induced or non-induced $E$. coli swelling in glycerol were considerably greater than for organisms incubated in dilute buffer for longer times. We concluded that either this spectrophotometric technique was not monitoring solely the permeation of glycerol into $E$. coli, or concentrations of glycerol above $100 \mathrm{~mm}$ significantly perturbed the structure of the $E$. coli cell envelope.
\end{abstract}

\section{INTRODUCTION}

Glycerol, which can serve as a carbon and energy source for Escherichia coli, is thought to penetrate the membrane of this organism either by passive permeation in glucose-grown cells or by facilitated diffusion in cells grown in the presence of glycerol or sn-glycerol 3-phosphate (Richey \& Lin, 1972; Sanno, Wilson \& Lin, 1968). One reason for studying this system is that it is the only known facilitated diffusion system in E. coli (Maloney, Kashket \& Wilson, 1975) and may be considered a prototype of carrier-mediated transport.

Non-electrolyte permeation in cells and phospholipid multilamellar vesicles (liposomes) is easily measured by the swelling rate assay. In this technique, uptake of the permeant molecules induces water influx and the resulting change in volume is monitored spectrophotometrically as a change in the absorbance of the suspension. This technique has been used to study the swelling of erythrocytes in glycerol (Stein, 1962), E. coli in lactose (West, 1970) and erythritol (Mitchell \& Moyle, 1956), and liposomes in various non-electrolytes (Bangham, De Gier \& Greville, 1967; De Gier, Mandersloot \& Van Deenen, 1968). Nonelectrolyte permeation in Acholeplasma laidlawii B and derived liposomes suspended in sucrose solution has been studied by measuring initial swelling rates following addition of permeant solution at the same tonicity as the sucrose solution (McElhaney, De Gier \& Van Deenen, 1970; De Gier et al., 1971; McElhaney, De Gier \& Van Der Neut-Kok, 1973; Read \& McElhaney, 1975; Van Zoelen et al., 1975). Acholeplasma laidlawii B behaves as an ideal osmometer over a considerable range of permeant concentrations and the initial swelling rate is linearly proportional to permeant concentration, as expected for a 
passive diffusional process. This approach has been extended to $E$. coli where, due to the rather small cell water volume and the rapid efflux of glycerol from this organism, many technical problems attend the use of radio-labelled glycerol to study initial rates of uptake (Maloney et al., 1975). It is not practical to make $E$. coli suspensions isotonic with the permeant solution since, under such conditions, the swelling amplitude is small. This may be due to the restraining effect of the wall on the swelling of the inner membrane. In practice, therefore, the cells are suspended in dilute buffer (Alemohammad \& Knowles, 1974; Richey \& Lin, 1972) and then mixed with hypertonic permeant solution made up in the same buffer. Thus, plasmolysis first occurs due to water efflux followed by permeant entry and swelling. Conventional spectrophotometry, however, can be used to measure only the passive process and not the facilitated diffusion, which is much too fast for this technique.

Alemohammad \& Knowles (1974) have described a stopped-flow spectrophotometric assay which can purportedly be used to measure the passive permeation of glycerol in non-induced $E$. coli as well as the facilitated diffusion of glycerol into induced cells. The swelling resulting from permeant entry leads to an increase in transmittance which is displayed on the screen of a storage oscilloscope. The reciprocal relaxation time $[1 / \tau$ corresponding to $k$ of Alemohammad \& Knowles (1974)] for the permeation is calculated from this trace. These authors contend that $1 / \tau$ can be considered to be constant as the glycerol concentration is varied, as expected for passive permeation. However, they actually report a deviation from constancy above $300 \mathrm{~mm}$-glycerol but ascribe this to refractive index differences. In this paper we present strong evidence, derived from a study of two strains of $E$. coli, that $1 / \tau$ is not constant for the passive process from $100 \mathrm{~mm}$ up to $500 \mathrm{~mm}$-glycerol, and that this deviation from constancy is due neither to refractive index differences nor to the presence of some residual level of the facilitator protein. Data from conventional spectrophotometry for the passive permeation of both glycerol and erythritol corroborate these results and suggest that this anomaly may apply to non-electrolyte passive permeation in $E$. coli in general. Thus the spectrophotometric technique of Alemohammad \& Knowles (1974) may not be exclusively measuring the permeation of glycerol into E. coli as previously assumed. Alternatively, glycerol at concentrations above $100 \mathrm{~mm}$ may be perturbing the structure of the $E$. coli envelope.

\section{METHODS}

Bacterial strains and growth conditions. Four E. coli strains were used: E. coli $\mathrm{K} 1060$, an unsaturated fatty acid auxotrophic mutant, was the generous gift of Dr David Silbert; wild-type E. coli $\mathrm{K}^{2} \mathrm{~F}^{-}$was kindly donated by Dr William Paranchych; while the two alkaline phosphatase-deficient strains, strain 7 (constitutive for the $g l p$ regulon) and strain E15 (inducible $g l p$ regulon) were the kind gifts of Dr Joel Weiner. Mutant k1060 was always grown in medium 63 (M63; Miller, 1972, p. 431) in the presence of unsaturated fatty acid (UFA) $\left(75 \mu \mathrm{g} \mathrm{ml}^{-1}\right)$ solubilized with $0.12 \%(\mathrm{w} / \mathrm{v})$ polyoxyethylene (20) cetylether (Brij 58 ), thiamin $\left(1 \mu \mathrm{g} \mathrm{ml}^{-1}\right), 0.3 \%(\mathrm{w} / \mathrm{v})$ Casamino acids and $0.4 \%(\mathrm{w} / \mathrm{v})$ glycerol or $0.23 \%(\mathrm{w} / \mathrm{v})$ xylose or $0.54 \%$ $(\mathrm{w} / \mathrm{v})$ glucose as carbon and energy source. Strains E15 and 7 were grown in medium 9 (M9; Alemohammad \& Knowles, 1974), or in M63 with or without UFA/Brij 58, and supplemented with nutrients as described for strain $\mathrm{K} 1060$. Strain $\mathrm{K} 12 \mathrm{~F}^{-}$was grown in trypticase soy broth without supplementation or in M9 (Alemohammad \& Knowles, 1974) or M63 with carbon source, Casamino acids and thiamin, but with or without UFA/Brij 58.

Organisms were first grown overnight in a small volume with rapid shaking (approx. $170 \mathrm{rev} . \mathrm{min}^{-1}$ ) at $37^{\circ} \mathrm{C}$ (or $39^{\circ} \mathrm{C}$ when elaidate-supplemented medium was used) in a New Brunswick Scientific Co. gyrotary shaker bath. The overnight culture was diluted 100 -fold in fresh medium and the shaking was continued till mid-exponential phase $\left(A_{550}=0.35\right.$ to 0.5$)$, when the organisms were harvested by centrifugation at $4{ }^{\circ} \mathrm{C}$ and $6000 \mathrm{~g}$ for $10 \mathrm{~min}$ in a Sorvall RC2-B centrifuge.

Media and chemicals. The following were purchased from J. T. Baker Chemical Co., Phillipsburg, New Jersey, U.S.A.: glucose, anhydrous dextrose, $[\alpha]_{\mathrm{D}}^{25}=52.9^{\circ}$, Analysed Reagent (AR); sucrose, crystalline, $[\alpha]_{\mathrm{D}}^{25}=66 \cdot 6^{\circ}, \mathrm{AR} ; \mathrm{D}(+)$-xylose, $[\alpha]_{\mathrm{D}}^{20}=+17^{\circ}$ to $+20^{\circ}$; glycerol, anhydrous, $99 \cdot 5 \%$ pure, AR; Tris buffer; meso-erythritol, $99 \%$. Imidazole, glucose-6-phosphate dehydrogenase and glucose 6-phosphate were from Sigma. Difco supplied vitamin-free Casamino acids and trypticase soy broth. Ficoll-400 was from Pharmacia. 
Preparation of $E$. coli for swelling rate assays. The organisms were washed three times in either $10 \mathrm{~mm}-$ imidazole $/ \mathrm{HCl}, \mathrm{pH} 7 \cdot 0$, or $5 \mathrm{~mm}$ Tris $/ \mathrm{HCl}, \mathrm{pH} 7 \cdot 5$, containing $1 \mathrm{~mm}-\mathrm{MgCl}_{2}\left(1 \mathrm{mM}-\mathrm{MgCl}_{2}\right.$ was found to be essential for the stability of cells of mutant $\mathrm{K} 1060$ suspended in dilute Tris buffer) and the final pellet was suspended to an $A_{550}$ of 0.35 for stopped-flow measurements. (Use of suspensions at one-half or twice this cell concentration made no difference to the values of $1 / \tau$ obtained.) The suspension was then left for at least $8 \mathrm{~h}$ at room temperature $\left(21\right.$ to $\left.23^{\circ} \mathrm{C}\right)$ for restoration of maximum osmotic sensitivity before use. For the complementary initial swelling rate assays employing the Zeiss PMQII spectrophotometer, the cell suspension was made about 10 times more concentrated.

Permeant solutions. Glycerol and erythritol solutions were made up in buffer identical to that in which the cells were suspended.

Refractive index correction in solutions. The synthetic polymer Ficoll-400 has a high refractive index ( $n$ ) but, since it also has a very high molecular weight, it has little effect on the osmotic pressure of a medium (Alemohammad \& Knowles, 1974; Netter, 1969). When Ficoll was used, the appropriate amount was added to each permeant (or sucrose) solution, as well as to the suspension of $E$. coli to bring the refractive indices to the same value; refractive indices were determined with an Abbe 3-L Bausch and Lomb refractometer. At room temperature the refractive index of aqueous solutions of Ficoll-400, sucrose or glycerol varied linearly with concentration within the ranges used. With $n=1.3332$ for water, the refractive index increments, $\Delta n$, were $1.48 \times 10^{-3}(\%)^{-1}$ for Ficoll-400, $5.0 \times 10^{-5} \mathrm{~mm}^{-1}$ for sucrose and $1.043 \times 10^{-5} \mathrm{~mm}^{-1}$ for glycerol. The osmolality of each solution was read from an Osmette $\mathbf{S}$ osmometer (Precision Systems, Waltham, Massachusetts, U.S.A.) and, within the range we used, showed no significant difference when Ficoll-400 was present.

Swelling assays. The swelling in glycerol of $E$. coli grown in the presence of glycerol or glucose was measured in a Durrum-Gibson stopped-flow spectrophotometer (Durrum Instrument Corporation, Palo Alto, California, U.S.A.); the initial swelling rates in erythritol, and also of glucose-grown cells in glycerol, were measured by conventional spectrophotometry using a Zeiss PMQII spectrophotometer. This was set up as previously described (McElhaney et al., 1973). During the latter assay, $500 \mu 1$ of E. coli suspension was pipetted into $4.0 \mathrm{ml}$ of hypertonic permeant solution in the water-jacketed cuvette containing a highspeed stirring bar.

The Durrum-Gibson stopped-flow spectrophotometer was set up essentially as described by Alemohammad \& Knowles (1974), except that the stop syringe assembly in the original apparatus (Gibson \& Milnes, 1964) was retained. This stop syringe activated a microswitch as soon as the suspension of $E$. coli from one drive syringe and the hypertonic glycerol solution from the other drive syringe entered the cuvette. The initial fast decrease in transmittance at $550 \mathrm{~nm}$ resulting from plasmolysis of the cells, and the subsequent increase in transmittance as glycerol entered the cells, was displayed as a trace on the screen of a storage oscilloscope. This second phase transmittance increase was allowed to continue to an asymptote, and then relaxation kinetic treatment (Daniels \& Alberty, 1966; Hague, 1969) was applied to calculate $1 / \tau\left(\mathrm{s}^{-1}\right)$ for glycerol permeation from a photograph of this trace, after having converted transmittance to absorbance using the Lambert-Beer law. The modification made by Alemohammad \& Knowles (1974), which excluded the stop syringe in order to prevent artefactual volume changes, was not necessary in our apparatus since this would only affect $1 / \tau$ for the first phase (transmittance decrease) due to water efflux and not $1 / \tau$ for glycerol entry in which we were interested and which occurred in the second phase (transmittance increase). Experiments were done at $550 \mathrm{~nm}$ except where otherwise stated.

Calculation of $1 / \tau\left(\mathrm{s}^{-1}\right)$. Since cell volume is linearly related to reciprocal absorbance (Bangham et al., 1967; McElhaney et al., 1973; and Fig. 1 in this paper, within the range of about 200 milliosmolal to at least 400 milliosmolal), change in volume, $\Delta \mathrm{vol}$, is directly proportional to change in reciprocal absorbance, $\Delta(1 / A)$, during the swelling of the cells. This has been applied in the calculation of $1 / \tau$ given below. However, Alemohammad \& Knowles (1974) calculated the rate constant $k\left(\mathrm{~s}^{-1}\right)$ for glycerol permeation assuming that change in volume, $\Delta \mathrm{vol}$, was proportional to change in absorbance, $\Delta A$. We have therefore used this assumed relationship for some calculations (where indicated) in order to be able to compare our data with those presented by these authors.

As stated above, we applied relaxation kinetics to calculate $1 / \tau\left(\mathrm{s}^{-1}\right)$ (Daniels \& Alberty, 1966; Hague, 1969) which, for the passive permeation process, has the same value as the first-order rate constant $k\left(s^{-1}\right)$ calculated by Alemohammad \& Knowles (1974).

$$
\Delta \mathrm{vol}_{t}=\Delta \mathrm{vol}_{\max } \times \mathrm{e}^{-t / \tau} \quad \text { i.e. }\left(\mathrm{vol}_{t}-\mathrm{vol}_{\infty}\right)=\left(\mathrm{vol}_{0}-\mathrm{vol}_{\infty}\right) \times \mathrm{e}^{-t / \tau}
$$

where vol $_{0}$ is the volume at a chosen zero point on the second phase of the trace (increasing transmittance); $\mathrm{vol}_{t}$ is the volume at time $t \mathrm{~s}$ relative to the chosen zero; and vol $_{\infty}$ is the volume of the cells at equilibrium (asymptote). Hence

$$
\ln \left[\frac{\mathrm{vol}_{t}-\mathrm{vol}_{\infty}}{\operatorname{vol}_{0}-\mathrm{vol}_{\infty}}\right]=\frac{-t}{\tau}
$$




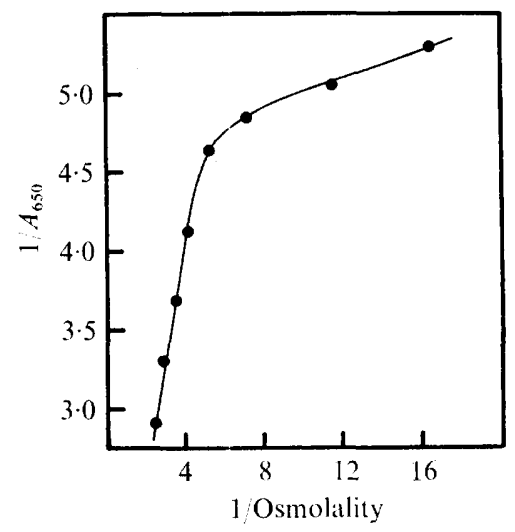

Fig. 1. Double reciprocal plot showing the relationship between cell volume $\left(1 / A_{650}\right)$ and reciprocal tonicity using Ficoll correction for refractive index. Escherichia coli k1060 was grown in M63 supplemented with xylose and oleic acid. The cells were harvested at mid-exponential phase, washed once with $250 \mathrm{~mm}$-sucrose containing $3 \cdot 365 \%(\mathrm{w} / \mathrm{v})$ Ficoll- 400 , and resuspended in the same solution. Samples $(50 \mu \mathrm{l})$ of this thick suspension were mixed with $3.75 \mathrm{ml}$ of sucrose solutions of various concentrations, the refractive indices of which had been adjusted (see Methods) to that of the $250 \mathrm{~mm}$-sucrose plus $3 \cdot 365 \%$ Ficoll solution. These suspensions were equilibrated for $2 \mathrm{~min}$ at room temperature and then absorbance at $650 \mathrm{~nm}$ was determined. The osmolal concentration of each of the sucrose solutions was also determined.

and since volume is proportional to $1 / A$,

$$
\ln \left[\frac{(1 / A)_{t}-(1 / A)_{\infty}}{(1 / A)_{0}-(1 / A)_{\infty}}\right]=\frac{-t}{\tau}
$$

Thus the slope of a plot of $\ln \left[\frac{(1 / A)_{t}-(1 / A)_{\infty}}{(1 / A)_{0}-(1 / A)_{\infty}}\right]$ versus $t$ is equal to $-1 / r$.

For calculating $k$, first-order kinetic treatment was applied as reported by Alemohammad \& Knowles (1974).

Enzyme assay. Glucose-6-phosphate dehydrogenase [D-glucose-6-phosphate : NADP+ 1-oxidoreductase; EC 1.1.1.49) was assayed as described by Langdon (1966), using a Beckman DBGT spectrophotometer equipped with a chart recorder.

\section{RESULTS}

Relationship between cell volume and reciprocal absorbance. Figure 1 relates the variation of reciprocal absorbance at $650 \mathrm{~nm}$ to the reciprocal osmolality of suspensions of $E$. coli $\mathrm{K} 1060$ in non-permeant sucrose solutions whose refractive indices $(n)$ had been adjusted to the same value with Ficoll-400. Since it has previously been demonstrated in other systems (McElhaney et al., 1973) that cell volume $(1 / A)$ is linearly dependent on the reciprocal tonicity of non-penetrant solute, we surmise that these cells behave as ideal osmometers in the concentration range 200 milliosmolal to at least 400 milliosmolal, obeying the Boyle-Mariotte-van't Hoff law (Netter, 1969) under these conditions. In these experiments, where absolute absorbance values were measured, the correction for refractive index was essential. In the swelling experiments, where changes in absorbance were monitored, we found that this correction for $n$ was not necessary (see Table 2).

Typical oscilloscope trace and calculation of $1 / \tau$. From the typical oscilloscope trace in Fig. 2, a $1 / \tau$ value of $0.095 \mathrm{~s}^{-1}$ was calculated (Fig. 3). The fact that the plot from which $1 / \tau$ was calculated was always a single straight line passing through the origin showed that there was no lysis of the cells during swelling. This conclusion was supported by the failure to detect glucose-6-phosphate dehydrogenase activity in $E$. coli suspended in hypertonic glycerol, unless the suspension was first treated with toluene (Miller, 1972, p. 353). 


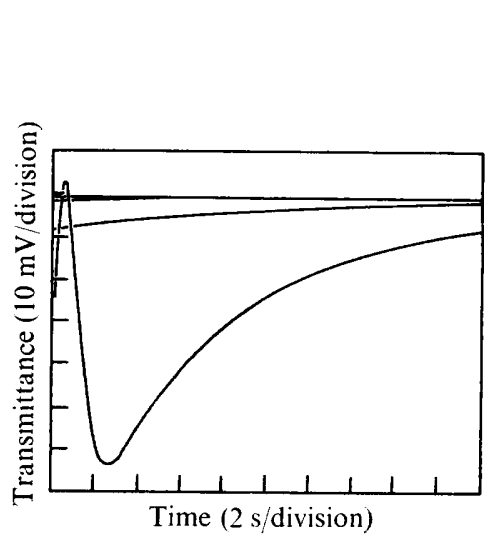

Fig. 2

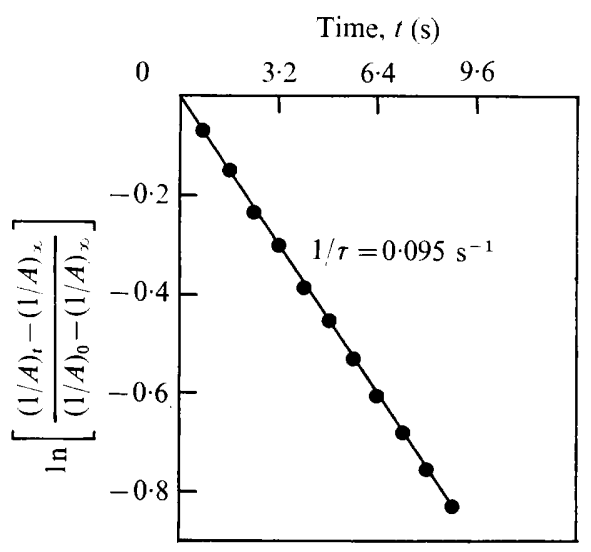

Fig. 3

Fig. 2. Typical oscilloscope trace. Escherichia coli $\mathrm{k} 1060$ was grown in M63 supplemented with oleic acid and glycerol and prepared as detailed in Methods. This trace was generated on treating the cells with $200 \mathrm{~mm}$-glycerol at $27 \cdot 8^{\circ} \mathrm{C}$.

Fig. 3. Determination of $1 / \tau\left(\mathrm{s}^{-1}\right)$ from the trace in Fig. 2. Points were taken from the second phase (transmittance increase), transmittance was converted to absorbance using the Lambert-Beer law and the calculation was effected as described in Methods.

Calculation of first-order rate constant. Data from oscilloscope traces obtained at $25{ }^{\circ} \mathrm{C}$ with different effective glycerol concentrations were used to determine the first-order rate constant $k$ (Fig. 4). Clearly, $k$ decreased as the permeant concentration increased between $75 \mathrm{~mm}$ and $500 \mathrm{~mm}$.

Neither the reciprocal relaxation time $\left(1 / \tau, \mathrm{s}^{-1}\right)$ nor the first-order rate constant $\left(k, \mathrm{~s}^{-1}\right)$ was constant for the passive permeation of glycerol into non-induced cells (Tables 1 and 2). The same trend, i.e. a decrease in $1 / \tau$ (or $k$ ) with increase in glycerol concentration, was observed irrespective of which parameter was measured for change in volume, $\Delta(1 / A)$ or $\Delta A$. This deviation from constancy was not a result of refractive index differences, since the same values were obtained from the same batch of cells (Table 2) whether or not refractive index was corrected for.

As indicated in Fig. 5(a), the deviation from linearity in the dependence of initial swelling rates on glycerol concentration was not due to the presence of a saturable component contributed by some residual level of the glycerol facilitator. Stein (1958) reported that $0.1 \mu \mathrm{M}-\mathrm{Cu}^{2+}$ is a potent inhibitor of the glycerol facilitator in erythrocytes. Glycerolfacilitated diffusion was completely inhibited by $0.5 \mu \mathrm{M}-\mathrm{CuCl}_{2}$ in $E$. coli $\mathrm{k} 1060$ grown in the presence of glycerol, but $\mathrm{CuCl}_{2}$ did not eliminate the anomalous behaviour in question. Organisms non-induced for the glycerol facilitator were grown in the presence of glucose. Glucose is known to repress the permeability of $E$. coli to glycerol (Sanno et al., 1968), probably by catabolite-repression of the synthesis of the facilitator protein. Aerobic glycerol-3-phosphate dehydrogenase activity could not be detected in membranes of cells grown in the presence of glucose (data not presented). This result supports the notion that glucose-grown $E$. coli was non-induced for Glp function, since it has been suggested (Sanno et al., 1968) that the system for glycerol-facilitated diffusion in $E$. coli belongs to the L- $\alpha-$ glycerophosphate regulon described by Cozzarelli, Freedberg \& Lin (1968), to which the aerobic glycerol-3-phosphate dehydrogenase also belongs. Similar trends in variation of $1 / \tau$ with concentration of glycerol were observed with induced cells although the values obtained were much higher.

Time dependence of the osmotic response. Alemohammad \& Knowles (1974) did not specify the time of incubation of $E$. coli in the dilute buffer before injection of the organisms 


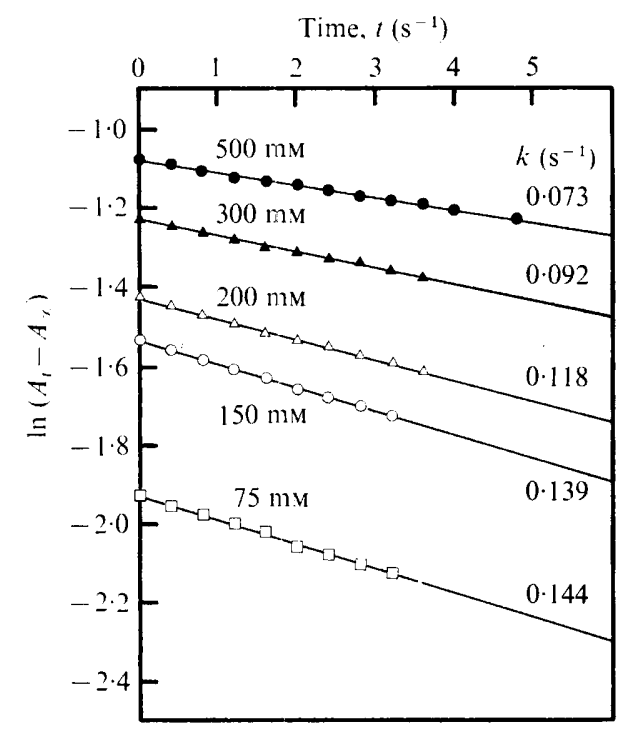

Fig. 4. Determination of first-order rate constants $\left(k, \mathrm{~s}^{-1}\right)$ for passive glycerol permeation at $25^{\circ} \mathrm{C}$

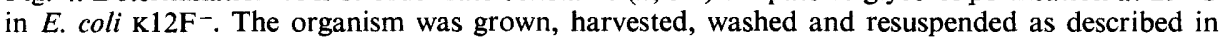
Table 1. Data from the stopped-fiow traces were plotted to determine $k$, assuming that $\Delta A \propto \Delta$ vol. Effective glycerol concentrations are indicated on the graphs.

Table $1.1 / \tau$ values for glycerol passive permeation in $E$. coli $\mathrm{K} 12 \mathrm{~F}^{-}$calculated on the basis of $\Delta(1 / A) \propto \Delta$ volume and also, for comparison, first-order rate constants $(k)$ for the same process calculated on the basis of $\Delta A \propto \Delta$ volume

Escherichia coli $\mathrm{K} 12 \mathrm{~F}^{-}$was grown in M9 plus glucose medium without UFA/Brij 58, as described in Methods. The cells were washed three times in $10 \mathrm{~mm}$-imidazole/ $\mathrm{HCl}, \mathrm{pH} 7 \cdot 0$, suspended to an $A_{550}$ of 0.35 in the same buffer and then equilibrated for $12 \mathrm{~h}$ before use.

$\begin{array}{ccc}\begin{array}{c}\text { Effective glycerol } \\ \text { concn (mM) }\end{array} & 1 / \tau\left(\mathrm{s}^{-1}\right) \text { at } 25^{\circ} \mathrm{C}^{*} & k\left(\mathrm{~s}^{-1}\right) \text { at } 25^{\circ} \mathrm{C} \dagger \\ 75 & 0.141 & 0.144 \\ 150 & 0.121 & 0.139 \\ 200 & 0 \cdot 108 & 0.118 \\ 300 & 0.077 & 0.092 \\ 500 & 0.056 & 0.073\end{array}$

* Calculated on the basis of $\Delta(1 / A) \propto \Delta$ vol.

$\dagger$ Calculated on the basis of $\Delta A \propto \Delta$ vol; data taken from Fig. 4.

into the hypertonic solution of permeant compound. We have observed, however, that all four $E$. coli strains tested were not osmotically sensitive immediately after washing with, and suspension in, dilute buffer. Irrespective of whether the cells were induced or noninduced for the glycerol facilitator, they required at least $8 \mathrm{~h}$ incubation at room temperature before adequate osmotic sensitivity was restored. If swelling experiments were done soon after the cells had been suspended in dilute buffer, the amplitude of swelling was small and $1 / \tau$ values were abnormally high. The absence of glucose- 6 -phosphate dehydrogenase in the suspending medium soon after suspension attested to the integrity of the inner membrane at this stage. The inner membrane could, none the less, be sufficiently leaky to small molecules like glycerol to prevent normal swelling. 
Table 2. $1 / \tau$ values for glycerol passive permeation in E. coli $\mathrm{K} 12 \mathrm{~F}^{-}$and $\mathrm{K} 1060$ determined in glycerol solutions adjusted to the same refractice index with Ficoll-400 or without such adjustment

Escherichia coli $\mathrm{K} 12 \mathrm{~F}^{-}$and $\mathrm{K} 1060$ were each grown in M63 plus glucose and oleic acid. The cells were harvested, washed three times (the former strain with $10 \mathrm{~mm}$-imidazole $/ \mathrm{HCl}, \mathrm{pH} 7 \cdot 0$, and the latter with $5 \mathrm{~mm}$-Tris $/ \mathrm{HCl}, \mathrm{pH} \mathrm{7.5}$, plus $1 \mathrm{~mm}-\mathrm{MgCl}_{2}$ ) and suspended to an $A_{550}$ of 0.35 in the same buffer. Suspensions were allowed to equilibrate before use (see Methods). The refractive index of each of one set of glycerol solutions (in the appropriate buffer) was adjusted with Ficoll-400 to that of the highest glycerol concentration used.

\begin{tabular}{|c|c|c|c|c|}
\hline \multirow{2}{*}{$\begin{array}{l}\text { Effective glycerol } \\
\text { concn (mM) }\end{array}$} & \multicolumn{2}{|c|}{$\begin{array}{c}\text { E. coli } \mathrm{K} 12 \mathrm{~F}^{-} \\
1 / \tau\left(\mathrm{s}^{-1}\right) \text { at } 25^{\circ} \mathrm{C}\end{array}$} & \multicolumn{2}{|c|}{$\begin{array}{c}\text { E. coli } \mathrm{K} 1060 \\
1 / \tau\left(\mathrm{s}^{-1}\right) \text { at } 26 \cdot 2^{\circ} \mathrm{C}\end{array}$} \\
\hline & Ficoll present & Ficoll absent & Ficoll present & Ficoll absen \\
\hline 100 & - & - & 0.073 & 0.073 \\
\hline 150 & $0 \cdot 111$ & $0 \cdot 109$ & - & - \\
\hline 200 & 0.099 & 0.093 & $0 \cdot 048$ & 0.048 \\
\hline 300 & 0.077 & 0.071 & 0.036 & 0.036 \\
\hline 400 & 0.062 & 0.059 & 0.029 & 0.029 \\
\hline
\end{tabular}
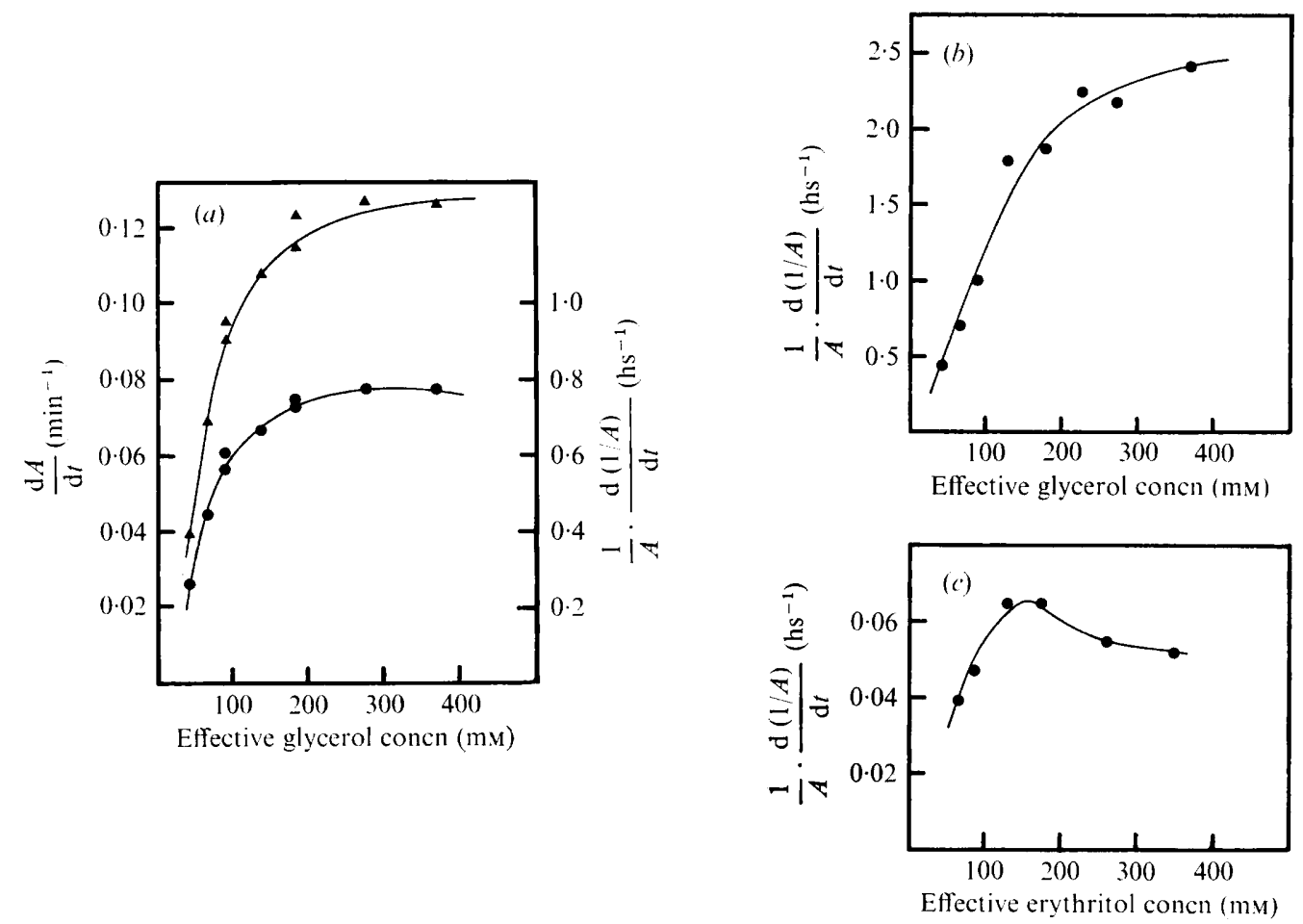

Fig. 5. Dependence of initial swelling rates of $E$. coli $\mathrm{k} 1060$ on glycerol or erythritol concentration, as measured by conventional spectrophotometry. The organism was grown in M63 supplemented with glucose and oleic acid and washed and prepared as described in Methods. (a) Initial swelling rates at $20^{\circ} \mathrm{C}$ in glycerol in the presence of $0.5 \mu \mathrm{M}-\mathrm{CuCl}_{2}: \bullet$, initial rates $\left[\frac{1}{A} \cdot \frac{\mathrm{d}(1 / A)}{\mathrm{d} t}\right]$ calculated on the basis of $\Delta(1 / A) \propto \Delta \mathrm{vol} ; \Delta$, initial rates $[\mathrm{d} A / \mathrm{d} t]$ calculated on the basis of $\Delta A \propto \Delta \mathrm{vol}$. (b) Initial swelling rates at $25^{\circ} \mathrm{C}$ in glycerol solutions whose refractive indices had been adjusted to the same value with Ficoll-400. (c) Initial swelling rates in erythritol at $30^{\circ} \mathrm{C}$. ( $\mathrm{hs}^{-1}$ denotes reciprocal hectoseconds.) 


\section{DISCUSSION}

The data presented show that during the swelling of $E$. coli in glycerol or erythritol, some as yet undetermined factors influence the parameters measured. Glycerol permeation in glucose-grown $E$. coli is assumed to occur by a passive process (Sanno et al., 1968) and as such, its $1 / \tau\left(\mathrm{s}^{-1}\right)$ or $k\left(\mathrm{~s}^{-1}\right)$ should be independent of the permeant concentration. One would therefore expect the initial rate of the same process to vary linearly as a function of permeant concentration. These predictions were not borne out by our results. However, for the simple prokaryote, Acholeplasma laidlawii $\mathrm{B}$, which lacks a cell wall, initial rates of glycerol (and other non-electrolyte) passive permeation, as measured by spectrophotometry, have been found to increase linearly with increasing permeant concentration (McElhaney et al., 1973).

These artefacts were still obtained after correction for refractive index was effected using Ficoll-400 (Table 2) and they were not eliminated by the presence of $0.5 \mu \mathrm{M}-\mathrm{CuCl}_{2}$. In addition, aerobic glycerol-3-phosphate dehydrogenase activity could not be detected in cells grown in the presence of glucose. It was, therefore, neither differences in refractive index nor some residual level of the glycerol facilitator which caused the artefacts.

The data presented by Alemohammad \& Knowles (1974) reveal that the same anomalous behaviour as we report here was also displayed in their system. These authors showed (in Fig. 6 of their paper) that $k\left(\mathrm{~s}^{-1}\right)$ for the passive permeation was approximately constant up to $300 \mathrm{~mm}$-glycerol but decreased dramatically and significantly between $300 \mathrm{~mm}$ and $500 \mathrm{~mm}$-glycerol. From this, one would predict that rates of this process should approach a plateau above $300 \mathrm{~mm}$-glycerol. Surprisingly, however, Fig. 7 of Alemohammad \& Knowles (1974) did not reflect this obvious prediction; rather, the rate of glycerol permeation seemed to increase linearly with the glycerol concentration up to $600 \mathrm{~mm}$. Even though these authors assumed that $k\left(\mathrm{~s}^{-1}\right)$ was constant from $150 \mathrm{~mm}$ to $300 \mathrm{mM}$-glycerol [Fig. 6 of Alemohammad \& Knowles (1974)], there was actually a slight but consistent decrease in this parameter as the permeant concentrations increased within this range.

Alemohammad \& Knowles (1974) also reported an Arrhenius plot for glycerol permeation in induced $E$. coli which showed a biphasic slope with a lower activation energy $\left(E_{\mathrm{a}}\right)$ below the phase transition temperature $\left(T_{\mathrm{c}}\right)$ than above it. We have obtained Arrhenius plots (data not shown) which, like that of these authors, are biphasic in slope for both induced and non-induced cells, but unlike theirs, we have consistently obtained higher $E_{\mathrm{a}}$ values below $T_{\mathrm{c}}$ than above it. Moreover, the position of $T_{\mathrm{c}}$ responded to the fatty acid enrichment of the membrane. For induced or non-induced cells of $E$. coli k1060 grown in the presence of oleic acid, $T_{\mathrm{c}}$ was $15^{\circ} \mathrm{C}$, and when grown on elaidic acid, $T_{\mathrm{c}}$ increased to $42^{\circ} \mathrm{C}$. Reports on other transport systems in an unsaturated fatty acid auxotroph of $E$. coli have shown biphasic Arrhenius plots for oleic acid- and elaidic acid-enriched membrane vesicles with $E_{\mathrm{a}}$ higher below $T_{\mathrm{c}}$ than above it (Shechter, Letellier \& Gulik-Krzywicki, 1974). We strongly suspect that the cause of the rather unusual apparent decrease in $E_{\mathrm{a}}$ below $T_{\mathrm{c}}$ reported by Alemohammad \& Knowles (1974) derives from the artefactual elevation of $1 / \tau$ obtained for glycerol permeation when organisms are used for swelling experiments soon after they have been washed with, and suspended in, dilute buffer. If swelling is measured 2 or $3 \mathrm{~h}$ after suspension, some swelling occurs but the amplitude is low and the calculated $1 / \tau$ (or $k$ ) is abnormally high. At later times (but less than $8 \mathrm{~h}$ ) the amplitude obtainable increases and concomitantly $1 / \tau$ decreases as long as the temperature is constant. So, in a situation where the cells have not been given sufficient time after suspension in dilute buffer, if temperature-dependence studies are done starting with swelling measurements at low temperatures and gradually working up to high temperatures, the $1 / \tau$ values obtained at low temperatures (before the cells have regained adequate osmotic sensitivity) are higher than the true values and such data would yield an Arrhenius plot exhibiting lower $E_{\mathrm{a}}$ at the lower temperatures than at higher temperatures. 
These apparent anomalies may in part be a consequence of the presence in $E$. coli of the two membrane systems and their enclosed periplasmic space and components, since they have not been observed in organisms lacking a cell wall. Alternatively, glycerol may be selectively perturbing the structure of the inner membrane in such a way as to decrease membrane lipid fluidity and thus the rate of permeation of glycerol. Whatever the basis of the anomalous behaviour observed here, it seems clear that one cannot assume that the spectrophotometric technique of Alemohammad \& Knowles (1974) is solely measuring the permeation of glycerol across the native plasma membrane of $E$. coli.

We would like to thank the following: Dr Neil Madsen, for having generously allowed us unrestricted use of the stopped-flow equipment; Dr Joel Weiner, for valuable discussions and suggestions; Mr Steve Cook and Mrs Nanette Mak, for excellent technical assistance; Mrs M. McCubbin, who carried out the osmometric determinations. This research was supported by grant MT 4261 from the Medical Research Council of Canada.

\section{REFERENCES}

Alemohammad, M. M. \& Knowles, C. J. (1974). Osmotically induced volume and turbidity changes of Escherichia coli due to salts, sucrose and glycerol, with particular reference to the rapid permeation of glycerol into the cell. Journal of General Microbiology 82, 125-142.

Bangham, A. D., De Gier, J. \& Greville, G. D. (1967). Osmotic properties and water permeability of phospholipid liquid crystals. Chemistry and Physics of Lipids 1, 225-246.

Cozzarelli, N. R., FreedberG, W. B. \& Lin, E. C. C. (1968). Genetic control of the L- $\alpha$-glycerophosphate system in Escherichia coli. Journal of Molecular Biology 31, 371-387.

Daniels, F. \& Alberty, R. A. (1966). Chemical kinetics. In Physical Chemistry, 3rd edn, pp. 325-330. New York: John Wiley.

De Gier, J., Mandersloot, J. G. \& Van Deenen, L. L. M. (1968). Lipid composition and permeability of liposomes. Biochimica et biophysica acta 150, 666-675.

De Gier, J., Mandersloot, J. G., Hupkes, J. V., McElhaney, R. N. \& Van Beek, W. P. (1971). On the mechanism of non-electrolyte permeation through lipid bilayers and through biomembranes. Biochimica et biophysica acta 233, 610-618.

Gibson, Q. H. \& Milnes, L. (1964). Apparatus for rapid and sensitive spectrophotometry. Biochemical Journal 91, 161-171.

Hague, D. N. (1969). Experimental methods for the study of fast reactions. In Comprehensive Chemical Kinetics, vol. 1, The Practice of Kinetics, pp. 112-133. Edited by C. H. Bamford and C. F. H. Tipper. Amsterdam: Elsevier.

LANGDON, R. G. (1966). Glucose-6-phosphate dehydrogenase from erythrocytes. Methods in Enzymology ix, 126-127.

Maloney, P. C., Kashiet, E. R. \& Wilson, T. H. (1975). Methods for studying transport in bacteria. In Methods in Membrane Biology, vol. 5, pp. 1-49. Edited by E. D. Korn. New York: Plenum Press.

McElhaney, R. N., De Gier, J. \& Van Deenen, L. L. M. (1970). The effect of alterations in fatty acid composition and cholesterol content on the permeability of Mycoplasma laidlawii B cells and derived liposomes. Biochimica et biophysica acta 219, 245-247.

McElhaney, R. N., De Gier, J. \& Van Der NEUT-KoK, E. C. M. (1973). The effect of alterations in fatty acid composition and cholesterol content on the nonelectrolyte permeability of Acholeplasma laidlawii B cells and derived liposomes. Biochimica et biophysica acta 298, 500512.

MilleR, J. (1972). Experiments in Molecular Genetics. New York: Cold Spring Harbor Laboratory.

Mitchell, P. \& Moyle, J. (1956). Osmotic function and structure in bacteria. Symposia of the Society for General Microbiology 6, 150-180.

NeTter, H. (1969). Osmosis. In Theoretical Biochemistry: Physico-chemical Principles of Vital Processes, English translation, pp. 102-103. New York: John Wiley.

ReaD, B. D. \& McElhaney, R. N. (1975). Glucose transport in Acholeplasma laidlawii $\mathbf{B}$ : dependence on the fluidity and physical state of membrane lipids. Journal of Bacteriology 123, 47-55.

RICHEY, D. P. \& LIN, E. C. C. (1972). Importance of facilitated diffusion for effective utilization of glycerol by Escherichia coli. Journal of Bacteriology 112, 784-790.

Sanno, Y., Wilson, T. H. \& Lin, E. C. C. (1968). Control of permeation to glycerol in cells of Escherichia coli. Biochemical and Biophysical Research Communications 32, 344-349.

Shechter, E., LeTEllier, L. \& GULIK-KRZYWICKI, T. (1974). Relations between structure and function in cytoplasmic membrane vesicles isolated from an Escherichia coli fatty acid auxotroph: high-angle X-ray diffraction, freeze-etch electron microscopy and transport studies. European Journal of Biochemistry 49, 61-76.

STEIN, W. D. (1958). N-terminal histidine at the active centre of a permeability mechanism. Nature, London 181, 1662-1663.

SteIN, W. D. (1962). Spontaneous and enzyme- 
induced dimer formation and its role in membrane permeability. I. The permeability of non-electrolytes at high concentration. Biochimica et biophysica acta 59, 35-46.

Van Zoelen, E. J. J., Van Der Neut-Kok, E. C. M., De Gier, J. \& Van Deenen, L. L. M. (1975). Osmotic behavior of Acholeplasma laidlawii B cells with membrane lipids in liquid-crystalline and gel state. Biochimica et biophysica acta 394, 463-469.

WeST, I. C. (1970). Lactose transport coupled to proton movements in Escherichia coli. Biochemical and Biophysical Research Communications 41, 655-661. 